\title{
Pengelolaan ZIS Dalam Upaya Meningkatkan Kesejahteraan Masyarakat Dan Penanggulangan Kemiskinan (Studi Deskriftif dan Preskriptif di BAZNAS Kabupaten/Kota di Eks-Karesidenan Surakarta)
}

\section{Muhammad Zumar Aminudin ${ }^{1}$, Lila Pangestu Hadiningrum ${ }^{2}$}

Fakultas Syariah Institut Agama Islam Negeri Surakarta

Email: Email: zumar1974@gmail.com dan lilahadiningrum@gmail.com

\begin{abstract}
Islam teaches to minimize the gap between the rich and the poor through the teachings of Zakat, Infaq and Alms (ZIS). Solo Raya includes a red zone of poor areas with diverse potential and problems. This study aims to determine the implementation and efforts that should be carried out by BAZNAS Regency / city in Solo Raya in the collection and distribution and utilization of ZIS in order to improve poverty and poverty alleviation. This research is a field research which is supported by a sociological juridical approach, because zakat is a legal act practiced in the community. Data collected by interview, observation and documentation techniques. Data analysis technique uses the constant comparative method.

The results showed that the collection of ZIS by BAZNAS in the Solo Raya Region generally relied on Civil Servants. The size of the results of the collection affects the programs that can be run. BAZNAS Regency / City of Solo Raya has distributed ZIS for consumptive interests for short-term and productive interests for the long-term interests. The efforts that should be carried out by Baznas in the collection, distribution and utilization of ZIS include: optimizing ZIS aware movements in various circles of society through various methods and social media, maximizing ZIS distribution services, playing an active role in zakat pick-up services as well as periodic guidance and mentoring of productive economic activities. The existence of effective ZIS management by Baznas in Wilayah Solo Raya is expected to be able to contribute in improving poverty and poverty alleviation.
\end{abstract}

Keywords: Management, ZIS, welfare, poverty 


\section{Pendahuluan}

Pada tahun 2015 dua kabupaten di Solo Raya, yaitu Sragen dan Klaten termasuk zona merah daerah miskin. Sementara Wonogiri, Karanganyar, Boyolali, dan Solo masuk zona kuning (http://www.solopos.com/2015/09/22/kemiskinan-soloraya-ini-dua-daerah-solorayamasuk-zona-merah-645218\#, diunduh pada tanggal 14 Desember 2017, jam 06.00 WIB). Pada Desember 2017 Wonogiri mengalami bencana banjir yang menelan kurban jiwa maupun harta. Kejadian ini tentu semakin meningkatkan angka kemiskinan daerah bersangkutan.

Untuk merealisasikan keadilan, selain memerintahkan agar umatnya berupaya menegakkannya, Islam juga mengajarkan secara langsung bagaimana meminimalisir kesenjangan melalui Zakat, Infak dan Sedekah (ZIS). Ketiganya merupakan cara redistribusi kekayaan agar tidak hanya dinikmati oleh orangorang kaya saja, tetapi juga dirasakan oleh orang-orang miskin. Di dalam AlQur'an terdapat 30 ayat tentang zakat, yang hampir semuanya dikaitkan dengan shalat (Qardhawi, 2007: 39). Hal ini menunjukkan bahwa kedudukan zakat setara dengan shalat.

Potensi zakat di Indonesia cukup besar. Menurut data Pusat Kajian Strategis Badan Amil Zakat Nasional (Baznas) potensi zakat nasional sebesar 217 triliun. Namun serapan zakat di Indonesia masih rendah. Pada 2016, tercatat zakat masuk Rp 5 triliun. Jumlah ini hanya 1 persen dari potensi yang ada (https://bisnis.tempo.co/read/880413/baznas-sebut-potensi-zakat-nasional-rp-271triliun, diunduh pada tanggal 14 Desember 2017, jam .06.00 WIB). Hal ini menunjukkan bahwa potensi yang sedemikian besar belum tergali dengan baik.

Jika dikelola dengan baik, zakat dapat berperan besar dalam pembangunan ini. Setidaknya, ada empat peran yang dapat dilakukan oleh zakat dalam pembangunan ini, yaitu: (1) memoderasi kesenjangan sosial; (2) membangkitkan ekonomi kerakyatan; (3) mendorong munculnya model terobosan dalam pengentasan kemiskinan; dan (4) mengembangkan sumber 
pendanaan pembangunan kesejahteraan umat di luar APBN maupun APBD (Puskaz BAZNAS, 2007: 53).

Sebenarnya sudah ada kebijakan negara mengenai zakat terutama setelah lahirnya Undang-undang Nomor 23 Tahun 2011 tentang Pengelolaan Zakat. Dari UU inilah lahir BAZNAS dan LAZ. Di seluruh kabupaten/kota se Solo Raya telah terbentuk BAZNAS kabupaten/kota, yaitu Kota Surakarta, Kabupaten Boyolali, Klaten, Wonogiri, Sukoharjo, Karanganyar dan Sragen. Masing-masing tentu memiliki potensi dan permasalahan yang berbeda.

Salah satu persoalan yang dihadapi BAZNAS Kabupaten/kota adalah belum optimalnya dana zakat yang masuk ke BAZNAS dibandingkan potensi yang ada. Secara nasional telah diuraikan sebelumnya. Sedangkan di daerah, sebagai gambaran jumlah Pegawai Negeri Sipil (PNS) di lingkungan Pemerintah Kota (Pemkot) Solo hingga pertengahan tahun 2017, hanya 10 persen PNS yang mengeluarkan zakat 2,5 persen dari penghasilannya ke Badan Amil Zakat Nasional (Baznas) Solo (https://www.merdeka.com/peristiwa/hanya10-persen-pns-solo-yang-mau-bayar-zakat.html, diunduh pada tanggal 15 Desember 2017 Jam 06.15 WIB). Sementara BAZNAS Kabupaten Karanganyar memperoleh pengelolaan terbaik tingkat nasional (https://news.okezone.com/read/2017/04/14/512/1667484/keren-karanganyar-sabet-2penghargaan-dari-menteri-agama, diunduh pada tanggal 16 Desember 2017 Jam 06.05 WIB).

Dari uraian di atas muncul pertanyaan mengenai apa yang telah dilakukan oleh BAZNAS di wilayah Solo Raya untuk meningkatkan pengumpulan ZIS maupun pendistribusian dan pendayagunaannya dalam rangka meningkatkan kesejahteraan dan penanggulangan kemiskinan. Pertanyaan lanjutan adalah apa yang semestinya dilakukan pada masa yang akan datang sesuai dengan potensi dan tantangan yang dihadapi oleh masingmasing daerah. Sejauh ini penelitian yang ada hanya mengungkapkan apa yang terjadi (deskriptif), yaitu apa yang telah dilakukan oleh BAZNAS, namun tidak merumuskan apa yang seharusnya dilakukan (preskriptif). Penelitian ini 
penting dikaji utuk bisa terjalin komunikasi antar daerah untuk saling belajar dan bekerja sama.

\section{Tinjauan Pustaka}

Penelitian mengenai zakat dan Penaggulangan Kemiskinan sebenarnya telah melimpah. Namun masih sedikit yang membahas BAZNAS di Solo Raya. Selain itu penelitian-penelitian yang sudah dilakukan hanya mengungkap apa yang sudah atau sedang terjadi. Sedangkan penelitian ini juga membahas apa yang semestinya dilakukan pada masa yang akan datang.

Penelitian-penelitian yang telah dilakukan dapat diperinci ke dalam kategori sebagai berikut:

a. Pengentasan kemiskinan melalui pemberdayaan zakat (Nur Ahmad, 2015: 89-108).

Penelitian ini adalah penelitian literer yang tidak berdasarkan kasus di lapangan. Penelitian ini mengungkapkan ciri-ciri orang miskin. Pertama, Tidak memiliki faktor produksi sendiri, seperti modal dan keterampilan. Kedua, Tidak memiliki kemungkinan aset produksi dengan kekuatan sendiri. Ketiga, Tingkat pendidikan yang rendah. Keempat, Pekerja musiman, hanya bekerja pada waktu tertentu saja, dan Kelima, Tidak memiliki keterampilan, sehingga tidak mampu bersaing dalam kehidupan. Dalam penelitan ini memaparkan peran zakat dalam mengentaskan kemiskinan. pertama, sudahkah sistem pengelolaan harta zakat dilandasi kesadaran untuk menjadi rahmat seluruh alam. Kedua, penyaluran zakat dituntut membangun mental mandiri sehingga mustahik bisa menjadi muzakki. Ketiga, amil zakat yang profesional tentu menjadi kebutuhan yang penting untuk menjamin dua poin di atas terlaksana, yakni penyadaran dan pemberdayaan.

b. Zakat: Solusi Pengentasan Kemiskinan (Nur Qomari, 2017: 15-25

Menurut artikel ini kemiskinan muncul karena ketidakberdayaan orang miskin karena kontruksi sosial yang sudah membentuknya. Kontruksi ini adalah akibat dari kebijakan struktur ekonomi, politik dan 
budaya yang tidak proporsional dan memihak. Dari pengumpulan zakat yang sudah mulai maksimal, secara otomstis penyalurannya juga maksimal. Untuk memaksimalkan penerimaan dana, tidak hanya zakat saja, tetapi juga dengan merampas hasil korupsi.

c. Intellectual Capital Badan Amil Zakat Dalam Pengelolaan Zakat (Fauziyatul Anshoriyyah, 2015: 67-92)

Artikel hasil penelitian lapangan di Bazda Surakarta (sebelum menjadi BAZNAS). Intellectual capital sendiri memiliki arti sebagai sebuah pengetahuan dan kemampuan yang dimiliki oleh organisasi/ perusahaan/ komunitas tertentu dalam menjalankan kegiatannya. Ada beberapa indikasi untuk mengukur kualitas sumber daya manusia, yaitu tingkat pendidikan, tingkat pengalaman, tingkat inovasi dan kreatifitas, structural capital (struktur organisasi dan hubungannya dengan lembaga terkait), relational capital (strategi alliances, licensing, agreements; relation with partners, supplier, and customer; serta knowledge about partners, suppliers).

d. Membedah Peran Strategis Manajemen Sumber Daya Manusia Dalam Pengelolaan ZIS (Tasnim Nikmatullah Realita dan Kasribening Menik, 2017)

Dalam makalah ini penulisnya secara garis besar menyatakan bahwa SDM Pengelola ZISWAF pada umumnya masih lemah. Padahal peranannya sangat besar bagi keberhasilan pengelolaan ZISWAF. Menurut penulis kriteria profesionalitas pengelola ZISWAF antara lain: Memiliki kompetensi, totalitas dalam bekerja. Mendapatkan payment ( upah), selalu ingin belajar, kesadaran bahwa perilaku dan tindakannya memiliki tanggung jawab sosial dan agama.

Penelitian ini berbeda dengan penelitian yang telah ada karena mengkaji implementasi serta upaya yang seharusnya dilakukan oleh BAZNAS Kabupaten/kota di Solo Raya dalam pengumpulan dan pendistribusian serta pendayagunaan ZIS dalam rangka peningkatan kesejahteraan dan penanggulangan kemiskinan. 


\section{Landasan Teori}

\section{Baznas}

Menurut Undang-undang pengelola ZIS ada dua, yaitu Badan Amil Zakat Nasional (BAZNAS) dan Lembaga Amil Zakat (LAZ). Sesuai dengan ketentuan dalam Undang-undang Nomor 23 Tahun 2011 tentang Pengelolaan Zakat bahwa yang dikelola oleh BAZNAS bukan hanya zakat tetapi juga meliputi infak dan sedekah (ZIS). Secara istilah zakat adalah sejumlah harta tertentu yang diwajibkan Allah diserahkan kepada orangorang yang berhak (Qardhawi, 2007: 34). Sedangkan menurut UU No 23 Tahun 2011 tentang Pengelolaan Zakat, Zakat adalah harta yang wajib disisihkan oleh seorang muslim atau badan yang dimiliki oleh orang muslim sesuai dengan ketentuan agama untuk diberikan kepada yang berhak menerimanya. Infak adalah harta yang dikeluarkan oleh seseorang atau badan usaha di luar zakat untuk kemaslahatan umum. Sedangkan Sedekah adalah harta atau nonharta yang dikeluarkan oleh seseorang atau badan usaha di luar zakat untuk kemaslahatan umum.

Secara teori ZIS dapat meningkatkan kesejahteraan umat dan menanggulangi kemiskinan jika dikelola dengan benar. Dalam rangka itulah negara membentuk lembaga yang mengelola zakat yang disebut Badan Amil Zakat Nasional (BAZNAS) sebagai amanat Undang-undang Nomor 23 Tahun 2011 tentang Pengelolaan Zakat.

Pasal 7 UU Pengelolaan Zakat menyatakan BAZNAS memiliki fungsi:

a. perencanaan pengumpulan, pendistribusian, pendayagunaan zakat;

b. pelaksanaan pengumpulan, pendistribusian, dan pendayagunaan zakat;

c. pengendalian pengumpulan, pendistribusian dan pendayagunaan zakat;

d. pelaporan dan pertanggungjawaban pelaksanaan pengelolaan zakat.

Namun untuk mewujudkan kesejahteraan masyarakat, Baznas memiliki visi dan misi. Misi BAZNAS antara lain adalah memaksimalkan 
peran zakat dalam menanggulangi kemiskinan di Indonesia melalui sinergi dan koordinasi dengan lembaga terkait.

Dengan fungsi dan misi demikian setidaknya ada tiga hal yang perlu diperhatikan, yaitu sumber daya manusia yang memadahi, pengumpulan yang maksimal serta pendistribusian dan pendayagunaan yang efektif.

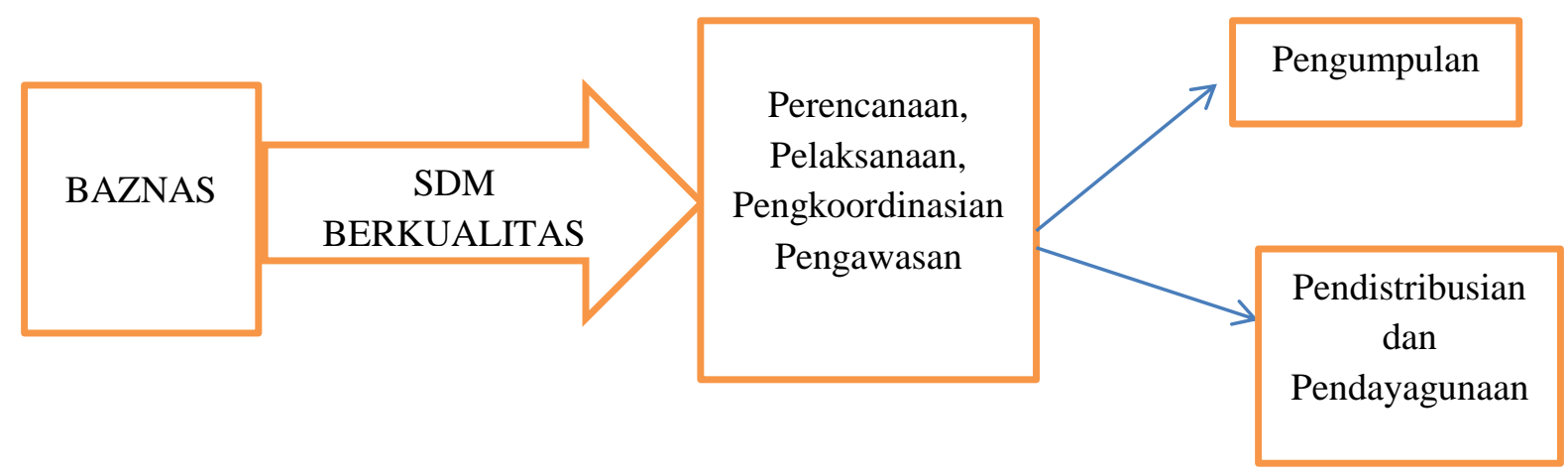

Sumber daya yang berkualitas antara memiliki kompetensi, totalitas dalam bekerja, mendapatkan payment (upah), selalu ingin belajar, memiliki kesadaran bahwa perilaku dan tindakannya memiliki tanggung jawab sosial dan agama. Sementara pengumpulan dan pendistribusian serta pendayagunaan zakat berhasil secara maksimal maka harus dilakukan secara kreatif dan inovatif. Hasil penelitian Balitbang Kemenag tahun 2015 menyebutkan bahwa Bazis yang dikelola oleh pemerintah daerah masih melakukan cara-cara yang konvensional. Hal ini berbeda dengan LAZ yang pengumpulan dana ZIS-nya sudah banyak melakukan inovasi produk yang sangat kompetitif dan terus membangun trust dari masyarakat (http://www.nu.or.id/post/read/72393/hasil-riset-lembaga-zakat-swasta-lebihkreatif-dan-inovatif, diunduh pada tanggal 17 Desember 2017 Jam 06.10 WIB). Bentuk inovasi itu perlu dilakukan selain pada aspek manajemen juga aspek normatifnya, misalnya dengan melakukan reinterpretasi mustahiq (Hamid Abidin, 2004). 


\section{Zakat, Infaq dan Sedekah}

Secara bahasa kata zakat (زكاة) berasal dari kata kerja زئ- يزكى yang merupakan fiil (kata kerja intransitif) yang berarti suci, tumbuh, berkah dan terpuji. Secara istilah zakat adalah sejumlah harta tertentu yang diwajibkan Allah diserahkan kepada orang-orang yang berhak (Qardhawi, 2007:34). Sedangkan menurut UU No 38 Tahun 1999 tentang Pengelolaan Zakat, Zakat adalah harta yang wajib disisihkan oleh seorang muslim atau badan yang dimiliki oleh orang muslim sesuai dengan ketentuan agama untuk diberikan kepada yang berhak menerimanya.

Sedangkan sedekah (صدقة) berasal dari kata صدق- يصدق yang berarti benar. Dalam hal ini benar pengakuan iman seseorang. Kata ini sering dipakai dalam ayat al-Qur'an untuk maksud zakat. Juga dipakai untuk maksud mahar. Cakupan kata ini juga meliputi hal-hal yang bersifat non-materiil, seperti mengucapkan kalimat thayyibah, senyum, hubungan suami istri dan melakukan kegiatan amar ma'fuf nahi munkar (Hafiduddin, 2002: 15). Dengan demikian cakupan shadaqah lebih luas dari pada zakat.

Sementara kata infaq (انفاق) berasal dari kata نقق - نيفق berarti menjadi miskin, habis perbekalan dan membelanjakan (Munawwir, 2007: 262). Kata ini mengacu secara lebih spesifik kepada harta (materi). Maka dalam kaitannya dengan harta, kata infaq lebih tepat dibanding kata shadaqah. Cakupan kata shadaqah juga lebih luas dari infaq. Maka kata infaq cocok untuk disandingkan dengan kata zakat, dimana zakat bersifat wajib sedangkan infaq bersifat sunnah. Namun demikian menurut Didin Hafiduddin keduanya memiliki makna yang sama, termasuk hukum dan ketentuan-ketentuannya (Hafiduddin, 2002: 15).

Bahkan dalam UU Pengelolaan Zakat muncul pula istilah lain selain zakat, infaq dan sedekah. Pasal 13 UU No. 23 Tahun 2011 tentang pengelolaan zakat menyatakan bahwa Badan Amil Zakat dapat menerima harta selain zakat, seperti infaq, shadaqah, hibah, wasiat, waris dan kifarat. Dengan demikian ketiganya perlu dibedakan, terutama antara kata infaq dan shadaqah. 


\section{ZISWAF; Jurnal Zakat dan Wakaf ( 2019, Vol. 6 No. 1)}

(P-ISSN : 2461-0577 ; E-ISSN : 2477-5347)

Di dalam UU Pengelolaan Zakat perbedaan antara zakat dan infak serta sedekah adalah bahwa bahwa zakat bersifat wajib, sedangkan infak dan sedekah bersifat sunah. Infak dan sedekah dibedakan dalam hal wujudnya, bahwa infak berwujud harta, sedangkan sedekah harta dan nonharta.

\section{Metode Penelitian}

Penelitian ini merupakan penelitian lapangan (field research) yang ditunjang dengan pendekatan yuridis sosiologis, karena zakat merupakan perbuatan hukum yang dipraktikkan di masyarakat. Dalam kajian sosilogis peneliti menahan diri untuk tidak terlibat pada persoalan yang dihadapinya, namun menerimanya sebagai sebuah kenyataan dan mencoba menganalisanya (Rahardjo, th: 17).

Dalam hal ini fakta-fakta yang akan diteliti adalah apa yang telah (deskriptif) dan seharusnya dilakukan (preskriptif) oleh BAZNAS Kabupaten/kota di Solo Raya dalam mewujudkan kesejahteraan dan menanggulangi kemiskinan. BAZNAS di Solo Raya terdiri dari 6 (enam) BAZNAS Kabupaten, yaitu Boyolali, Klaten, Wonogiri, Sukoharjo, Karanganyar dan Sragen serta 1 (satu) Baznas kota, yaitu Surakarta. Sumber data dalam penelitian ini adalah : Pengurus BAZNAS, khususnya baitul mal sebagai sumber data primer. Dalam kaitannya dengan pelaksanaan pendistribusian, juga akan dikonfirmasi kepada para mustahiq. Mustahiq zakat produktif yang diambil secara purposif sampling. Dokumen-dokumen mengenai BAZNAS di Solo Raya serta Kamus dan ensiklopedia sebagai sumber data tersier. Teknik pengumpulan data dilakukan dengan wawancara, observasi dan dokumentasi.

Wawancara adalah metode pengumpulan data dengan cara komunikasi melalui kontak atau hubungan pribadi antara peneliti dengan responden (Adi, 2004: 72). Dalam penelitian ini teknik ini digunakan untuk mengumpulkan data dari sumber-sumber primer, yaitu para pengurus 


\section{ZISWAF; Jurnal Zakat dan Wakaf ( 2019, Vol. 6 No. 1)}

(P-ISSN : 2461-0577 ; E-ISSN : 2477-5347)

BAZNAS dan Mustahiq. Wawancara dilakukan secara setengah terstruktur dengan panduan pertanyaan sebagai acuan.

Teknik observasi atau pengamatan bertujuan untuk mendeskripsikan perilaku dalam kenyataan (Adi, 2004: 71). Perilaku dalam kenyataan tidak hanya meliputi perilaku manusia, namun juga termasuk kondisi tempat atau barang yang tidak bernyawa. Teknik ini digunakan untuk mengumpulkan data dari sumber data yang berupa program pendistribusian ZIS. Teknik dokumentasi digunakan untuk menelaah dan mengumpulkan bahan-bahan kepustakaan dari sumber-sumber data sekunder dan tersier.

Data-data dideskripsikan dan dianalisis secara kualitatif dengan metode perbandingan tetap (constant comparative method) yang meliputi reduksi data, kategorisasi dan sintesisasi, serta perumusan jawaban (Moleong, 2009: 288-289). Setelah direduksi, data dikategorisasikan, yaitu dipilah ke dalam bagian yang memiliki kesamaan. Berikutnya adalah sintesisasi, yaitu mengaitkan antara satu kategori data dengan kategori data yang lain sehingga tersusun jalinan yang dapat memberi penjelasan atas permasalahan penelitian. Langkah terakhir adalah penyusunan jawaban, yaitu pernyataan proposisional yang terkait dengan data dan merupakan jawaban atas permasalahan penelitian.

\section{Hasil dan Pembahasan}

Upaya meningkatkan kesejahteraan masyarakat tidak hanya dilihat dari penthashorufan atau pendistribusian ZIS saja, namun juga upaya pengumpulannya. Pertama, karena BAZNAS memang bukan hanya lembaga penyalur ZIS, tetapi juga pengumpul. Kedua, semakin banyak ZIS yang berhasil dikumpulkan, semakin banyak program untuk meningkatkan kesejahteraan massyarakat. Sebaliknya semakin ZIS yang terkumpul, semakin sedikit pula program yang bisa dilaksanakan. 


\section{A. Baznas Kabupaten Sukoharjo}

\section{Profile Lembaga}

BAZNAS Sukoharjo telah memiliki kantor sendiri sejak tahun 2016 di Jalan Rajawali Kalurahan Joho Kecamatan Sukoharjo kabupaten Sukoharjo Jawa Tengah. Kantor yang cukup representatif ini berdiri di atas tanah kas pemerintah daerah Sukoharjo. Kepengurusan Baznas sesuai dengan Surat Keputusan Bupati Sukoharjo Nomor 451 /325/ 2017 tentang Pengukuhan Anggota Baznas Kabupaten Sukoharjo Periode 2017 - 2022.

Dilihat dari visi dan misinya BAZNAS Sukoharjo memiliki orientasi meningkatkan kesejahteraan masyarakat, terutama kelompok mustahiq, lebih khusus lagi fakir miskin. Obsesinya bahkan tidak hanya meningkatkan kesejahteraan, tetapi bahkan merubah mustahiq menjadi muzakki. Hal itu berarti orang yang semula menerima zakat karena statusnya fakir miskin menjadi orang yang membayar zakat, infaq atau sedekah. Orang yang membayar ZIS tentu orang yang bukan fakir miskin lagi.

\section{Pengumpulan ZIS}

a) Sasaran

Masyarakat umum memang belum menjadi sasaran untuk dijadikan muzakki, baru PNS/ASN. Di samping itu sumber daya yang dimiliki oleh BAZNAS Sukoharjo juga terbatas.

Penyaluran ZIS ke BAZNAS dilakukan oleh satuan kerja yang ada di Kabupaten Sukoharjo. Dalam laporan akhir tahun 2017 cukup banyak, bahkan hampir semua lembaga yang ada di Kabupaten Sukoharjo telah menyalurkan ZISnya ke BAZNAS, bahkan tidak hanya lembagaa yang berada di bawah Pemda, namun juga yang berada di bawah pemerintah pusat, misalnya lembaga-lembaga yang berada di bawah Kemenag. Berikut ini gambaran lembaga yang telah menyalurkan ZISnya ke BAZNAS Sukoharjo: 


\begin{tabular}{|l|l|l|l|l|l|}
\hline Badan/Dinas/Kantor & $\begin{array}{l}\text { BUMN/BUMD/ } \\
\text { Swasta }\end{array}$ & Sekolahan & $\begin{array}{l}\text { UPTD } \\
\text { Pendidikar }\end{array}$ & Kecamatan & Kalurahan \\
\hline 34 & 10 & 62 & 12 & 12 & 17 \\
\hline
\end{tabular}

Sumber: Diolah dari Laporan BAZNAS yang dimuat di Buletin BAZNAS Kabupaten Sukoharjo Edisi 002 Tahun 2017

b) Kerja sama deengan Pemerintah Daerah dan Kemenag

BAZNAS Sukoharjo menjalin kerja sama dengan Pemerintah Daerah dalam berbagai bentuk. Kerja sama ini sangat penting, mengingat keduanya sama-sama unsur pemerintah. Pemda adalah unsur pemerintah struktural, sedangkan BAZNAS unsur pemerintah non-struktural. Keduanya memiliki tujuan yang kurang lebih sama, yaitu mensejahterakan masyarakat. Maka kerja sama keduanya sangat penting. Terlebih lagi sasaran donator BAZNAS Sukoharjo sejauh ini masih PNS.

c) Penerbitan Buletin

Sosialisasi yang lain yang lebih modern adalah dengan membuat buletin yang diedarkan ke berbagai instansi sejak tahun 2017. Pelayanan yang disediakan dalam bentuk rekening juga sangat terbatas. Bahkan dalam satu kecamatan bisa lebih dari satu kantor layanan BRI.

\section{Pendistribusian}

Pentasarufan juga tidak seluruhnya ditangani oleh BAZNAS Sukoharjo. Sebagian dilakukan oleh UPZ (Unit Pengumpul Zakat). UPZ yang melakukan pentasarufan antara lain UPZ Kemenag, UPZ MTsN Sukoharjo, MTsN Bendosari dan MTsN Bekonang. Semua UPZ tersebut merupakan lembaga yang bernaung di bawah pemerintaah pusat, bukan Pemda Sukoharjo. Pentasarufan dalam bentuk bantuan konsumtif dan produktif (bantuan modal). Dalam kerangka zakat produktif, zis diberikan dalam bentuk modal usaha, baik untuk usaha baru maupun usaha lama. BAZNAS Sukoharjo memberikan bantuan dalam bentuk barang maupun 


\section{ZISWAF; Jurnal Zakat dan Wakaf ( 2019, Vol. 6 No. 1)}

(P-ISSN : 2461-0577 ; E-ISSN : 2477-5347)

uang. Penerimanya tentu saja pedagang kecil. Modal barang berupa peralatan yang dibutuhkan untuk usaha. Misalnya gerobak dorong untuk jualan jus dan gerobak dorong untuk jualan HIK. Sedangkan uang diberikan untuk modal dagang sayur matang dan sosis bakar (Rita Putri Hardini, Tanggal 23 Juli 2018 di kantor BAZNAS Sukoharjo).

Kesejahteraan yang ditopang oleh BAZNAS Sukoharjo tidak hanya kesejahteraan materiil, tetapi juga kesejahteraan spiritual. Kesejahteraan materiil terlihat dari bantuan-bantuan yang diberikan kepada masyarakat tidak mampu, baik yang bersifat konsumtif maupun yang bersifat produktif. Sedangkan kesejahteraan materiil berupa bantuan sarana dan prasarana ibadah dan partisipasi kegiatan.

\section{B. BAZNAS Karanganyar}

\section{a. Profile Lembaga}

Alamat kantor Baznas karanganyar adalah Jl. Lawu Kabupaten Karanganyar, Jawa Tengah Telp. (0271) 495005 Email: baznaskra@gmail.com. Biaya operasional baznas Karanganyar berasal dari amil dan APBD. Adapun biaya ini dipergunakan untuk penggajian, sosialisasi, peralatan kantor, membayar tagihan listrik, air, serta untuk keperluan rapat. Status tanah Baznas Surakarta adalah dari Pemda.

\section{b. Pengumpulan ZIS}

Dalam upaya memaksimalkan pengumpulan ZIS BAZNAS Kabupaten Karanganyar telah melakukan berbaagai program, terutama pada sosialisasi. Sosialisasi merupakan program strategis. Secara konseptual BAZNAS kabupaten Karanganyar menentukan strategi sebagai berikut: membangun kepercayaan, memperteguh kebersamaan, memperluas jaringan, mengoptimalkan pengumpulan dan mengefektifkan pendistribusian. Muzakki Baznas Karanganyar berasal dari PNS dan masyarakat luas. Baznas Kabupaten Karanganyar berwenang melakukan pengumpulan zakat melalui unit pengumpul zakat (UPZ) Kantor Satuan Kerja (SKPD), kantor instansi vertikal 
tingkat kabupaten, perusahaan swasta skala kabupaten, masjid, mushola, langgar, surau, sekolah Madrasah dan Lembaga Pendidikan, Kecamatan, Desa dan Kelurahan.

Beberapa upaya yang dilakukan Baznas Karanganyar agar penerimaan maksimal antara lain:

1) Sasaran

Sasaran utama untuk dijadikan muzakki adalah Pegawai Negeri Sipil. Hal ini bisa dimaklumi, karena sebagai lembaga pemerintah (non-struktural) BAZNAS tentu lebih mengutamakan orang-orang yang bekerja pada pemerintahan, yaitu PNS. Seandainya seluruh PNS dapat tertangani sudah bagus.

2) Sosialisasi

Layanan merupakan bagian yang sangat penting untuk menarik minat masyarakat menyalurkan ZIS nya ke BAZNAS Karanganyar. Bagi masyarakat yang berpengalaman, cukup banyak pilihan penyaluran zakat, terutama LAZ yang sebagian sudah cukup professional dalam memberikan layanan kepada muzakki. Untuk memudahkan muzaki membayar zakat antara lain: Transfer rekening, datang langsung melalui conter Baznas, melalui UPZ Kemitraan, melalui bank, Layanan Jemput Zakat

3) Dukungan pemda

Mengingat BAZNAS merupakan lembaga pemerintah, meskipun non structural, maka kerja sama dengan Pemerintah Daerah sangat penting. Pemerintah Daerah Kabupaten Karanganyar telah memberikan dukungan kepada BAZNAS Karanganyar, baik materiil maupun kebijakan. Besarnya dana yang masuk setiap bulan kurang lebih 1 M. Secara keseluruhan perolehan ZIS Baznas Kabupaten Karanganyar dari tahun 2015 (6.867.065.800), tahun 2016 (10.214.522.323) dan tahun 2017 (13.260.551.131). Hal ini menunjukkan pengumpulan ZIS dari 
tahun ke tahun mengalami fluktuasi namun secara keseluruhan mengalami peningkatan.

\section{c. Pendistribusian}

Planning baznas dalam pendistribusian zakat melalui Rentsra 5 tahunan yang dituangkan dalam Rencana Kerja Anggaran Tahunan (RKAT) yang mengacu pada 5 program yang meliputi bidang ekonomi (Karanganyar makmur), bidang pendidikan (Karanganyar cerdas), bidang kesehatan (Karanganyar sehat), bidang da'wah (Karanganyar Takwa) dan bidang sosial (Karanganyar peduli). Pendistribusian berdasarkan 8 asnaf yang dijabarkan dalam bentuk program dan kegiatan. Penjabaran program dalam bentuk kegiatan disesuaikan dengan kondisi masyarakat, yang disepakati oleh pimpinan Baznas Kabupaten Karanganyar. Kebijakan penyaluran ZIS Basnas Karanganyar meliputi: $10 \%$ program kemanusiaaan (fakir, miskin, gharimin, ibnu sabil), $15 \%$ program kesehatan (fakir dan mualaf), 25 $\%$ program pendidikan (fakir, miskin, mualaf, fisabilillah dan ibnu sabil), $15 \%$ program ekonomi (fakir, miskin, mualaf, gharimin) dan 35 $\%$ program dakwah (mualaf dan fisabilillah). Adapun bentuk pentasyarufan/pendistribusiannya berupa sembako, bantuan modal, beasiswa, RTLH dan Jamban Sehat, uang bantuan desa, uang santunan penyandang folio dan ghorim).

\section{BAZNAS Sragen}

1. Profil

BAZNAS Kab. Sragen memiliki jaringan Unit Pengumpul Zakat (UPZ) sebanyak 148 (Seratus Empat Puluh Delapan) yang tersebar di kantor, dinas, instansi, badan pemerintah dan swasta di wilayah Kabupaten Sragen dan beberapa bank yang menjadi mitra. Selain itu ada 8 UPZ Masjid dan 1 UPZ Pontren yang menjadi jaringan dari BAZ Kabupaten Sragen. 


\section{Pengumpulan}

Dalam upaya untuk memaksimalkan pengumpulan ZIS BAZNAS Sragen telah melakukan berbagai upaya, diantaranya adalah :

a) Sasaran

Sasaran utama untuk menjadi donator (Muzakki, munfiq maupun mutashoddiq) adalah pegawai negeri sipil (PNS). Sosialisasi dilakukan dengan sosialisasi BAZNAS Sragen kepada para ASN se-Kabupaten Sragen, sosialisasi Buletin Zakkaha, sosialisasi melalui Radio Buanaa Asri Sragen. BAZNAS Kabupaten Sragen juga melakukan sosialisasi secara langsung dengan mendatangi daerah-daerah yang menurut pemantauan BAZNAS masih minim tingkat kesadaran tentang ZIS, mendatangi majelis-majelis taklim, silaturrahmi khusus kepada muzakki potensial, maupun dengan meminta disediakan waktu di selasela pertemuan para pimpinan daerah guna mensosialisasikan tentang pentingnya peran zakat, infak dan shadaqah dalam perekonomian umat.

b) Layanan Pengumpulan

Muzakki, munfiq atau muthasoddiq yang akan menyalurkan zisnya diberi beberapa alternative layanan, yang meliputi: datang ke BAZNAS Kabupaten Sragen, transfer melalui rekening, pembentukan Unit Pengumpul Zakat (UPZ). Selain upaya di atas BAZNAS Sragen juga mengembangkan unit pendidikan dan usaha. Unit Pendidikan meliputi: Play Group dan Taman Kanak - Kanak Islam Unggulan (PG dan TKIU) BAZSRA. Pendidikan dalam prpgram pengembangan BAZ, 20\% gratis untuk para anak dari mustahik. Dan sekolah tersebut juga boleh untuk anak dari para muzakki tetapi bayar. Artinya dalam program pengembangan pendidikan ini ada ruang. Unit Ekonomi Syariah berupa Koperasi Jasa Keuangan Syarieeah Lembaga Ekonomi Syarie ah Badan Amil Zakat ( KJKS - LES BAZ). 


\section{c). Pendistribusian}

Pendistribusian ZIS di BAZNAS SRagen dapat dilihat dari dua perspektif. Pertama dari perspektif kelembagaan dan kedua dari perspektif mustahiqnya. Dilihat dari perspektif kelembagaan ada divisi, yaitu divisi pendistribusian (sragen peduli, sragen takwa) dan divisi pemberdayaan (sragen cerdas, sragen sejahtera, sragen sehat). Sragen Peduli meliputi program tanggap musibah, santunan lansia jompo, santunan keluarga miskin, santunan musafir kehabisan bekal. Sragen Taqwa meliputi bantuan Ormas Islam, Insentif Kyai dan Ustadz Pondok Pesantren, Insentif Ustadz Madin, Santunan Penjaga Masjid seKabupaten Sragen, Santunan Muallaf, Santunan Santri Ponpes/ Panti Asuhan Islam, Bina Tempat Ibadah (Sertifikasi Tanah Wakaf). Sragen Cerdas meliputi Bantuan biaya Pendidikan Siswa SMA/SMK/MA, Bantuan biaya Pendidikan Perguruan Tinggi dan Mahasiswa Asuh, Insentif Guru PAI Tidak Tetap (GTT) pada TK, SD, SMP, SMA dan SMK. Sragen Sejahtera meliputi Modal usaha Dhuafa, Program Ekonomi Produktif, Gerobak Hik dan Modal Usaha Awal, Peduli Warga Binaan Lembaga Permasyarakatan Sragen, Baznas Sragen melakukan pembinaan sampai benar-benar mustahik tersebut bisa mandiri. Sragen Sehat meliputi: Perbaikan Rumah Tidak Layak Huni (RTLH), bantuan Operasional Rawat Inap Keluarga Miskin Muslim, ambulan Gratis

\section{BAZNAS Surakarta}

a. Profile

BAZNAS Surakarta terletak di Jl. Ki Mangun Sarkoro No. 115, Sumber, Surakarta Telp. 0271-719040, Hotline : 081393055550 (SMS/WA/Telepon), E-Mail : baznaskota.surakarta@baznas.go.id. Status tanah masih sewa. Terdapat 8 orang pengurus di Baznas Kota Surakarta yang meliputi ketua, bidang pengumpulan, bidang pendistribusian dan pendayagunaan, bidang perencanaan, keuangan dan 
pelaporan, bidang administrasi sumber daya manusia dan umum, fundrasing, planing dan financial serta administrasi. Dalam upaya memaksimalkan pengumpulan ZIS, BAZNAS Kota Surakarta telah melakukan berbagai langkah:

1) Sasaran

Sebagai lembaga plat merah (lembaga Pemerintah) yang berarti yang diharapkan untuk menjadi muzakki adalah para ASN (PNS) walaupun tidak menutup dari kalangan swasta untuk menjadi muzakki. Beberapa dari kalangan swasta yang menjadi muzakki di Baznas Surakarta antara lain: individu, BMT Dana Mulia, DokterDokter (RS.Muwardi dan UNS).

2) Sosialisasi

Upaya yang sudah dilakukan oleh Baznas Surakarta agar penerimaan zakat di Baznas maksimal antara lain: Sosialisasi yang dilakukan di Dinas-dinas, UPZ, Media Pemkot, pamflet, Spanduk, dan Pengajian.

3) Dukungan Pemkot Surakarta

Dukungan Pemda ke Baznas Surakarta dalam bentuk Surat Edaran Walikota No. 451.12/586.1 tahun 2007 pada masa Walikota Bapak Jokowi dilanjutkan Surat Edaran Nomor 451.12/843 Tentang Pungutan Zakat, Infak dan Sedekah yang disahkan walikota Surakarta Bapak FX. Hadi Rudyatmo. Besaran rata-rata dana yang masuk Baznas Surakarta setiap bulan kurang lebih 100 juta.

b. Pendistribusian

Dalam pendistribusian zakat baznas Surakarta mempunyai planning berupaya mensejahterakan masyarakat dengan target $1 \mathrm{M}$ tiap bulan, dan tidak ada dana yang mandeg. Sasaran pendistribusian zakat diprioritaskan pada 8 asnaf. Rincian penyaluran baznas kota Surakarta periode Januari sampai dengan Juni 2018 meliputi fakir miskin 63\%, Fii sabilillah $19 \%$, ibnu sabil 0,57\% dan amil. Bentuk pentasyarufannya/pendistribusiannya berupa sembako, bantuan modal, 
beasiswa, dan lain-lain. Penyaluran Baznas Surakarta untuk fakir miskin diprioritaskan pada sektor pendidikan $56 \%$, kegiatan Ekonomi produktif $17 \%$, Kesehatan $6 \%$ dan lain-lain $22 \%$.

\section{E. BAZNAS Klaten}

1. Profile

Kantor di Komplek masjid Raya Klaten, sejak 2 Tahun yang lalu, tepatnya tahun 2016. Sasaran Muzakki BAZNAS Kabupaten Klaten sejauh ini sama dengan Kabupaten lain, yaitu PNS. Baznas memberikan keleluasaan kepada masyarakat untuk kesadaran ZIS nya namun Baznas sudah berupaya secara optimal dalam memberikan sosialisasi ke kecamatan-kecamatan.Pemerintah Daerah Kabupaten Klaten sudah memberikan dukungan terhadap program-program BAZNAS, baik secara materiil maupun spiritual. Pihak BAZNAS melihat secara top down, bukan buttom up. Artinya BAZNAS berpikir secara subyektif bahwa program mereka baik dan cocok untuk mustahiq. Mungkin memang program yang ditawarkan baik, tujuannya juga baik. Namun belum tentu cocok. Selain itu mungkin perlu pendekatan yang komprehensif. Permasalahan kemiskinan sesungguhnya cukup kompleks, sehingga tidak cukup hanya didekati dengan satu pendekatan.

Adanya pemberian bantuan fakir miskin, program ekonomi kreatif dan pemberian beasiswa diharapkan mampu memberikan kontribusi dalam meningkatkan kesejahteraan umat.

\section{Kesimpulan}

Rata-rata Muzakki PNS di atas $90 \%$ dari keseluruhan Muzakki. Sebagian sudah cukup maksimal, seperti Karanganyar dan Sragen, sebagian masih belum maksimal, seperti Klaten dan Sukoharjo serta Surakarta. Dalam upaya pengumpulan ini BAZNAS sebenarnya cukup diuntungkan dengan adanya dukungan dari Pemerintah Daerah maupun instansi terkait, misalnya Kemenag 
Kabupaten/Kota. Ada BAZNAS yang telah melakukan terobosan dengan membuka lembaga pendidikan dan Koperasi jasa keuangan Syariah. Dalam upaya meningkatkan kesejahteraan dan penanggulangan kemiskinan BAZNAS Kabupaten/Kota telah mendistribusikan ZIS untuk kepentingan konsumtif untuk kepentingan jangka pendek dan produktif untuk kepentingan jangka panjang. Seluruh BAZNAS Kabupaten/kota yang menjadi obyek penelitian ini telah mendorong masyarakat tidak mampu untuk menjadi pengusaha. Rekomendasi yang dapat dilakukan oleh Baznas Solo raya dalam pengumpulan, pendistribusian serta pendayagunaan ZIS dalam rangka peningkatan kesejahteraan dan penanggulangan kemiskinan pada masa yang akan datang meliputi: memanfaatkan dukungan Pemerintah Daerah dan Instansi terkait untuk meningkatkan pengumpulan ZIS. Sumber daya yang lebih muda sangat diperlukan untuk akselerasi kinerja serta melihat kemiskinan secara komprehensif, tidak hanya persolan modal usaha maupun ketrampilan usaha, tetapi juga mentalitas. Oleh sebab itu pendekatan yang perlu dilakukan tidak semata-mata pendekatan ekonomi, tetapi juga pendekatan budaya.

\section{Daftar Pustaka}

Abidin, Hamid (Editor), 2004, Reinterpretasi Pendayagunaan ZIS Menuju Efektifitas Pemanfaatan ZIS, Jakarta: Piramedia

Ahmad, Nur, Pemberdayaan Kemiskinan Melalui Pemberdayaan Zakat, Jurnal ZISWAF, Vol. 2, No. 1, Juni 2015, Program Studi Zakat dan Wakaf Jurusan Syariah dan Bisnis Islam STAIN Kudus

Anshoriyah, Fauziyatul dkk, Intellectual Capital Badan Amil Zakat Dalam Pengelolaan Zakat, Jurnal Spirit Publik, Program Studi Administrasi Negara Fakultas Ilmu Sosial dan Politik Universitas Sebelas Maret Volume 10, Nomor 1 April 2015

Asmaroini, Ambiro Puji, Menjaga Eksistensi Pancasila Dan Penerapannya Bagi Masyarakat di Era Globalisasi, artikel di Jurnal Jurnal Pancasila dan Kewarganegaraan, Vol. 1, No. 2, Januari 2017, Universitas Muhammadiyah Ponorogo

Divisi Publikasi dan Jaringan Puskas BAZNAS, 2017, Outlook Zakat Indonesia 2017, Jakarta: PUSKAS BAZNAS 
Hafidhuddin, Didin, 2002, Zakat dalam Perekonomian Modern, Jakarta:Gema Insani.

Munawir, 2007, Kamus Arab-Indonesia Al-Munawir, Surabaya: Pustaka Progresif.

Moleong, J. Lexy 2009, Metodologi Penelitian Kualitatif, cet. 26, Bandung : Remaja Rosda Karya

Qomari, Nur, Zakat:Solusi Pengentasan Kemiskinan, Jurnal Iqtishodia , Program Studi Ekonomi Syariah Jurusan Syariah dan Ekonomi Islam STAIN Kudus, (2017) Vol.02 No.02

Qordhawi, Yusuf, 2007, Hukum Zakat, cet. 10, terjemahan Salman Harun dkk, Jakarta: Litera AntarNusa

Realita, Tasnim Nikmatullah dan Kasribening Menik, Membedah Peran Strategis Manajemen Sumber Daya Manusia (Sebuah Kajian Konseptual), Makalah pada Seminar Seminar Nasional \& Call For Paper, FEB Unikama "Peningkatan Ketahanan Ekonomi Nasional Dalam Rangka Menghadapi Persaingan Global'Malang, 17 Mei 2017

Renan, Ernest, 1994, Apakah Bangsa Itu ?, Alih Bahasa Sunario,Bandung: Alumni

Rianto Adi, 2004, Metodologi Penelitian Sosial dan Hukum, Jakarta : Granit Satjipto Rahardjo, tt, Hukum Dan Masyarakat, Bandung : Aksara

Sudibyo, Bambang, Strategi Zakat Nasional 2015-2020, makalah disampaikan pada Seminar Nasional "Filantropi Islam Kontemporer : Potensi, Organisasi dan Pengembangan SDM, yang diselenggarakan oleh Fakultas Syariah IAIN Surakarta pada tanggal 31 Agustus 2016 di Hotel Syariah Surakarta

Sumber Internet:

https://bisnis.tempo.co/read/880413/baznas-sebut-potensi-zakat-nasional-rp-271triliun, diunduh pada tanggal 14 Desember 2017, jam .06.00 WIB https://www.merdeka.com/peristiwa/hanya-10-persen-pns-solo-yang-mau-bayarzakat.html, diunduh pada tanggal 15 Desember 2017 Jam 06.15 WIB https://news.okezone.com/read/2017/04/14/512/1667484/keren-karanganyarsabet-2-penghargaan-dari-menteri-agama, diunduh pada tanggal 16 Desember 2017 Jam 06.05 WIB

http://www.nu.or.id/post/read/72393/hasil-riset-lembaga-zakat-swasta-lebihkreatif-dan-inovatif, diunduh pada tanggal 17 Desember 2017 Jam 06.10 WIB 